\title{
AaPDR3, a PDR Transporter 3, Is Involved in Sesquiterpene $\beta$-Caryophyllene Transport in Artemisia annua
}

\author{
Xueqing Fu, Pu Shi, Qian He, Qian Shen, Yueli Tang, Qifang Pan, Yanan Ma, Tingxiang Yan, \\ Minghui Chen, Xiaolong Hao, Pin Liu, Ling Li, Yuliang Wang, Xiaofen Sun and \\ Kexuan Tang *
}

Joint International Research Laboratory of Metabolic and Developmental Sciences, Key Laboratory of Urban Agriculture (South) Ministry of Agriculture, Plant Biotechnology Research Center, Fudan-SJTU-Nottingham Plant Biotechnology R\&D Center, School of Agriculture and Biology, Shanghai Jiao Tong University, Shanghai, China

\section{OPEN ACCESS}

Edited by:

Wanchai De-Eknamkul, Chulalongkorn University, Thailand

Reviewed by:

Tetsuo Kushiro,

Meiji University, Japan

Guodong Wang,

Institute of Genetics and Developmental Biology (CAS), China

*Correspondence: Kexuan Tang kxtang@sjtu.edu.cn

Specialty section:

This article was submitted to Plant Metabolism and Chemodiversity,

a section of the journal

Frontiers in Plant Science

Received: 17 February 2017 Accepted: 19 April 2017

Published: 08 May 2017

Citation:

Fu X, Shi P, He Q, Shen Q, Tang Y, Pan Q, Ma Y, Yan T, Chen M, Hao X, Liu P, Li L, Wang Y, Sun $X$ and Tang $K$ (2017) AaPDR3, a PDR Transporter 3,

Is Involved in Sesquiterpene $\beta$-Caryophyllene Transport in Artemisia annua. Front. Plant Sci. 8:723. doi: 10.3389/fp/s.2017.00723
Artemisinin, a sesquiterpenoid endoperoxide, isolated from the plant Artemisia annua L., is widely used in the treatment of malaria. Another sesquiterpenoid, $\beta$-caryophyllene having antibiotic, antioxidant, anticarcinogenic and local anesthetic activities, is also presented in $A$. annua. The role played by sesquiterpene transporters in trichomes and accumulation of these metabolites is poorly understood in $A$. annua and in trichomes of other plant species. We identified $A a P D R 3$, encoding a pleiotropic drug resistance (PDR) transporter located to the plasma membrane from $A$. annua. Expression of $A a P D R 3$ is tissue-specifically and developmentally regulated in $A$. annua. GUS activity is primarily restricted to T-shaped trichomes of old leaves and roots of transgenic $A$. annua plants expressing proAaPDR3: GUS. The level of $\beta$-caryophyllene was decreased in transgenic $A$. annua plants expressing AaPDR3-RNAi while transgenic $A$. annua plants expressing increased levels of AaPDR3 accumulated higher levels of $\beta$-caryophyllene. When AaPDR3 was expressed in transformed yeast, yeasts expressing AaPDR3 accumulated more $\beta$-caryophyllene, rather than germacrene $D$ and $\beta$-farnesene, compared to the non-expressing control.

Keywords: Artemisia annua L., sesquiterpene, ABC transporter, $\beta$-caryophyllene, pleiotropic drug resistance (PDR) transporter

\section{INTRODUCTION}

ATP-binding-cassette $(\mathrm{ABC})$ proteins are one of the biggest protein families in plants, which function as channels, molecular switches, and transporters (Sugiyama et al., 2006). ABC transporters are divided into different subfamilies depending on the combination of the structural elements (Verrier et al., 2008). One family of these, pleiotropic drug resistance (PDR) transporters, the full size ABCG subfamily, consist of two transmembrane domains (TMDs) and two nucleotide binding domains (NBDs). The NBDs contain Walker A motifs, Walker B motifs, and the ABC signature motifs (Biemansoldehinkel et al., 2006). In plants, PDR transporters are reported to be involved in varieties of biological functions, including terpenoids and phytohormone transport, cuticular formation, defense against pathogens, and resistance to cadmium and lead 
(Jasiński et al., 2001; Lee et al., 2005; Stukkens et al., 2005; Ito and Gray, 2006; Kobae et al., 2006; Strader and Bartel, 2009; Kang et al., 2010; Kim et al., 2010; Bessire et al., 2011). The first plant PDR transporter, SpTUR2, was cloned from Spirodela polyrrhiza, which might play a role in response to conditions inhibiting plant growth (Smart and Fleming, 1996). Then SpTUR2 was conferred on the resistance to the antifungal diterpene sclareol (Van Den Brûle et al., 2002). The work on ABC transporters in Nicotiana plumbaginifolia showed that $N p A B C 1$ was regulated by the antifungal diterpenes sclareol and sclareolide in cell cultures (Jasiński et al., 2001). Subsequently NpPDR1 was reported to be involved in the secretion of defense-related metabolites (Stukkens et al., 2005). And the expression of NtPDR1 in Nicotiana tabacum BY2 cells and transport tests suggested that NtPDR1 was involved in diterpene transport to defend against biotic threats (Crouzet et al., 2013). Besides, it has been reported that (AtPDR12)/ABCG40 mediates cellular uptake of the phytohormone abscisic acid (Kang et al., 2010). Furthermore, some PDR transporters were reported to contribute to heavy metals resistance, such as cadmium $\left(\mathrm{Cd}^{2+}\right)$ and lead $\left(\mathrm{Pb}^{2+}\right)($ Lee et al., 2005; Kim et al., 2007). Cadmium and lead are common pollutants in soil, which are dangerous to plants growth (Raskin et al., 1997; Lanphear, 1998). In plants, AtPDR8-overexpressing plants showed stronger $\mathrm{Cd}^{2+}$ or $\mathrm{Pb}^{2+}$ resistance, and AtPDR8 RNAi transgenic plants and T-DNA insertion lines were more sensitive to $\mathrm{Cd}^{2+}$ or $\mathrm{Pb}^{2+}$ compared to wild-type plants (Kim et al., 2007). AtPDR12, an $A B C$ transporter, was reported to contribute to $\mathrm{Pb}^{2+}$ resistance in Arabidopsis (Lee et al., 2005).

Artemisia annua L., a traditional Chinese medicinal plant, is famous for producing the sesquiterpenoid endoperoxide artemisinin. Artemisinin-based combination therapies (ACTs) are a recommended treatment against the cerebral and chloroquine-resistant malaria by the World Health Organization (WHO; White, 2008). In addition to artemisinin, a large number of monoterpenes, sesquiterpenes, and triterpenes are presented in A. annua with functions in growth, development and defense in plants (Wei et al., 1992; Fulzele et al., 1995; Holm et al., 1997; Tellez et al., 1999; Bhakuni et al., 2001; Goel et al., 2007). In fact, the monoterpenes from A. annua contain the regular monoterpenes, the rearranged monoterpenes, and the irregular monoterpenes (Charles et al., 1991; Woerdenbag et al., 1994; Jia et al., 1999). The sesquiterpenes $\beta$-caryophyllene, $\beta$ farnesene, germacrene $\mathrm{D}$, germacrene $\mathrm{A}$, amorphadiene, and epi-cedrol were isolated from A. апnиа (Fulzele et al., 1995; Bouwmeester et al., 1999; Juteau et al., 2002). Monoterpenes and sesquiterpenes as the major volatile compounds of plants are usually emitted to defend against biotic threats (Degenhardt et al., 2003). For example, (E)- $\beta$-farnesene (E $\beta F$ ) is an important volatile compound of plants, which functions as the main component of the aphid alarm pheromones (Bowers et al., 1972; Pickett and Griffiths, 1980; Francis et al., 2004). A sesquiterpene, $\beta$-caryophyllene, is distributed in essential oils of plants with the anti-inflammatory, antibiotic, antioxidant, anticarcinogenic, and local anesthetic activities (Legault and Pichette, 2007). The triterpenoids include sterols, steroids, and saponins, are a large and structurally diverse group of natural products, derived from squalene (Xu et al., 2004).
With so many varieties, the sesquiterpene biosynthesis network is quite complicated in A. annua (Figure S1). Fortunately, several sesquiterpene synthases have been reported from A. апnиа. Sesquiterpenes, like artemisinin, are synthesized via the direct precursor farnesyl diphosphate (FPP) in plants. In sesquiterpene biosynthesis, FPP is converted to an array of cyclization products, such as amorpha-4,11-diene, $\beta$-caryophyllene, $\beta$-farnesene, germacrene $A$, and epi-cedrol, by amorpha-4,11-diene synthase (AaADS; Bouwmeester et al., 1999), $\beta$-caryophyllene synthase (AaCPS; Cai et al., 2002), $\beta$-farnesene synthase (AaBFS; Picaud et al., 2005), germacrene A synthase (AaGAS; Bertea et al., 2006), and epi-cedrol synthase (AaECS; Mercke et al., 1999) respectively in A. annua. In addition, it is well-known that geranyl diphosphate (GPP) is the precursor of monoterpenes. The formation of monoterpene linalool is catalyzed by linalool synthase (AaLAS; Jia et al., 1999). Squalene synthase (AaSQS) is a key enzyme of sterol and triterpene pathway (Liu et al., 2003). The synthesis of triterpene $\beta$-Amyrin is catalyzed by $\beta$-Amyrin synthase (AaBAS).

There are two kinds of trichomes in A. annua, glandular trichomes and T-shaped trichomes, in which large quantities of secondary metabolites are synthetized, stored and volatilized to protect plants against plant pathogens, neighboring plants, insects, and herbivores (Wagner, 1991; Duke and Paul, 1993; Pichersky and Gershenzon, 2002). The glandular trichomes where artemisinin biosynthesis occurs, contains two stalk cells, two basal cells, and three pairs of secretory cells (Duke and Paul, 1993; Olsson et al., 2009). By contrast, the research on T-shaped trichomes is still largely unknown. Previous studies demonstrated that AaCPS was primarily located in T-shaped trichomes, roots, buds, and flowers, while AaBFS was expressed in T-shaped trichomes, glandular trichomes, and roots (Wang et al., 2013, 2014). The transcriptome of T-shaped trichomes was sequenced using Illumina RNA-Seq. The result showed that the specific terpene metabolic pathways were also existed in the Tshaped trichome (Soetaert et al., 2013). In one publication, the authors cloned PDR1 and PDR2 transporters from A. annua and suggested that PDR2 was related to artemisinin biosynthesis in tobacco, although the substrate was not verified (Wang et al., 2016).

Therefore, these findings indicate that the multicellular T-shaped trichomes have the capacity to synthesize and store large quantities of sesquiterpenes in A. апnиа. Numerous studies have identified genes related to sesquiterpenes biosynthesis in $A$. annua, but little is known about the sesquiterpenes transport. Hence, it will be interesting to investigate sesquiterpenes transporters in the biofactories. Here, we identified a PDR transporter PDR3 (AaPDR3) from the T-shaped trichomes RNAseq databases, which is specifically expressed and developmentally regulated in A. annua. The decrease and increase in the transcript levels of AaPDR3 in the RNAi and overexpression plants resulted in the decrease and increase of $\beta$-caryophyllene contents, respectively. Besides, when AaPDR3 was expressed in yeast, $\beta$-caryophyllene was accumulated faster than the control. From these results, we identified a PDR transporter involved in $\beta$-caryophyllene transport in A. annua. 


\section{EXPERIMENTAL PROCEDURES}

\section{Plant Material and Growth Conditions}

A. annua named as "Huhao 1," originated from Chongqing, was developed in Shanghai after selection for several years. Plants were grown in the greenhouse with a $16 / 8 \mathrm{~h}$ light/dark photoperiod at $25^{\circ} \mathrm{C}$.

\section{Isolation and Characterization of AaPDR3}

T-shape trichomes were collected from the capitulum of $A$. annua with laser capture microdissection. The RNA from Tshape trichomes was extracted and sequenced (Soetaert et al., 2013). Arabidopsis ABC protein sequences were obtained from the Arabidopsis Information Resource (TAIR) database. A. annua putative $\mathrm{ABC}$ transporters were searched performing a BLASTP analysis against the transcriptome database using Arabidopsis ABC transporter protein sequences as queries with an " $E$ " value over $\mathrm{e}^{-120}$. Then the sequences of polypeptides corresponding to A. annua $\mathrm{ABC}$ transporters were analyzed in the Conserved Domain Database (CDD) at NCBI (Cakir and Kilickaya, 2013). The ABC transporters protein sequences from A. annua and PDR protein sequences from Arabidopsis were aligned with ClustalX. The phylogenetic tree was constructed by MEGA software (Tamura et al., 2011). Based on the RNAseq databases, we predicted the full-length AaPDR3 sequence. To obtain the open reading frame (ORF) of AaPDR3, the cDNA was synthesized with $0.5 \mu \mathrm{g}$ total RNA isolated from leaves of A. annua, and the ORF was amplified using the gene-specific primers (Table S1). The phylogenetic tree analysis was performed with MEGA software version 5 via the neighbor-joining method based on amino acid sequence alignment, and the bootstrap analysis was performed using 1,000 replicates. Roots, stems, young leaves (the two youngest leaves), old leaves (from the 15 th to the 16th leaf), buds and flowers of the A. annua plants were collected for RNA extraction using plant RNA isolation reagent (Tiangen, Beijing, China) following the manufacturer's instructions. The leaves from the Leaf0 (meristem), Leaf1, Leaf2, Leaf3, Leaf4, Leaf5, and Leaf6 counted from the apical top of the main stem were collected from 5-month-old A. annua. The total RNA was used to synthesize the first-strand cDNA. All the tissues and leaves collected from three plants were separately pooled for each determination. For hormone treatment, 2-month-old $A$. annua plants were treated with $100 \mu \mathrm{M}$ MeJA (Sigma-Aldrich, USA), and then sampled at $0,0.5,1.5,3,6,9,12,24 \mathrm{~h}$, water with $1 \%$ concentration of DMSO as a mock treatment. The fifth leaves collected from three plants were separately pooled for each determination for RNA isolation. Real-time qPCR was carried out using the SuperReal PreMix Plus (SYBR Green) kit (Tiangen, Beijing, China) on lightcycle ${ }^{\circledR} 96$ (Roche, Mannheim, Germany). Three biological repeats were measured for each sample.

\section{Subcellular Localization of AaPDR3}

The full-length ORF of $A a P D R 3$ was cloned into BamHI and $\mathrm{XbaI}$ sites of $\mathrm{pHB}-\mathrm{GFP}$ vector. The recombinant plasmid was introduced into Agrobacterium tumefaciens strain GV3101 for A. tumefasciens-based Nicotiana benthamiana leaves transient expression (Voinnet et al., 2003). To confirm the localization of AaPDR3, we co-expressed the fusion protein GFP-AaPDR3 and the plasma membrane protein PIP1-mCherry in tobacco leaf epidermal cells. The GFP signal was observed after 2-3 days by Leica TCS SP5-II confocal laser microscopy (Leica, Wetzlar, Germany).

\section{Molecular Cloning of AaPDR3 Promoter and Promoter-GUS Fusions in Transgenic}

\section{A. annua}

Genomic DNA was extracted from fresh young leaves of $A$. annua using the CTAB method. The upstream region 2,059 bp of $A a P D R 3$ was obtained from the genome database of $A$. annua, amplified from genomic DNA with primers containing PstI and BamHI restriction sites and inserted into pCAMBIA1391Z vector. The resulting construct was transformed into $A$. annua plants, as described previously (Zhang et al., 2009).

\section{Construction of Plant Expression Vector and Transformation of $A$. annua}

The $346 \mathrm{bp}$ fragment of AaPDR3 was amplified, cloned into gateway cloning vector pENTR vector using pENTR $^{\mathrm{TM}} / \mathrm{SD} / \mathrm{D}-\mathrm{TOPO}{ }^{\circledR}$ Cloning Kit (Invitrogen, Carlsbad, CA, USA), and then transferred to the destination vector pHELLSGATE12 via the LR recombination reaction (Invitrogen). The recombination plasmids (pHB-GFP$A a P D R 3$ and pHELLSGATE12-iAaDPR3) were introduced into $A$. tumefaciens strain EHA105 and transformed into A. annua plants, as described previously (Zhang et al., 2009).

\section{Histochemical GUS Staining and Western Blot Analysis}

The leaves were sampled from non-transgenic plants and transgenic plants for the histochemical GUS staining (Jefferson, 1987). The photographs were taken using an optical microscope (OLYMPUS, Japan). Two hundred milligrams of young leaves were powdered in liquid nitrogen, solubilized in the 2 volumes of buffer (100 mm Tris-HCl [pH 8], $50 \mathrm{~mm} \mathrm{KCl,} 10 \mathrm{~mm}$ $\mathrm{MgCl}$, $20 \mathrm{~mm}$ DTT, and 2\% Trixon-100) containing the protease inhibitors Cocktail and $1 \mathrm{mM}$ phenylmethylsulfonylfluoride for $20 \mathrm{~min}$ on ice and centrifuged at $10,000 \mathrm{~g}$ for $10 \mathrm{~min}$ at $4^{\circ} \mathrm{C}$ twice. The supernatant was denatured by $2 \mathrm{x}$ sample buffer (125 mm TrisHCl [pH 6.8], 20\% glycerol, 4\% SDS, $200 \mathrm{~mm}$ DTT, and $0.05 \%$ bromophenol blue), incubated at $60^{\circ} \mathrm{C}$ for $15 \mathrm{~min}$ and clarified by centrifugation at $10,000 \mathrm{~g}$ for $1 \mathrm{~min}$. The protein samples were separated on $8 \%$ SDS-PAGE gels and transferred onto nitrocellulose filters $(0.45 \mu \mathrm{m}$ pore size) (Millipore, USA). The membranes were blocked in 5\% (w/v) nonfat milk powder for $2 \mathrm{~h}$, and incubated with a 1:20,000 dilution of the primary antibody (Abmart, China) at $4^{\circ} \mathrm{C}$ overnight. The membranes were washed, incubated with a 1:10,000 dilution of goat anti-mouse alkaline phosphatase-conjugated secondary antibody (Sigma, USA), and detected using eECL Western Blot Kit (Kangwei Bio Inc., China). 


\section{GC-MS Analysis}

The fresh samples were ground into fine powder in liquid nitrogen and freeze-dried for $72 \mathrm{~h}$ at $-50^{\circ} \mathrm{C}$. Fifty milligrams powder was suspended in $4 \mathrm{~mL}$ chromatographic-grade hexane in $10 \mathrm{~mL}$ glass tube with $100 \mu \mathrm{L}$ trans-farnesol $(77.6 \mu \mathrm{g} / \mathrm{mL})$ as the internal standards, vigorously vortexed for $1 \mathrm{~min}$ and extracted for $40 \mathrm{~min}$ in an ultrasonic processor (JYD-650; Shanghai Zhisun Instrument Co. Ltd, China). The samples were centrifuged at $4,000 \mathrm{~g}$ for $10 \mathrm{~min}$. The supernatants were filtered through $0.25-\mu \mathrm{m}$-pore-size filters, then concentrated and redissolved in $200 \mu \mathrm{L}$ chloroform. GC-MS analysis was performed according to the methods described previously (Zhang et al., 2009). Three biological repeats were measured for each sample. Germacrene D was purchased from ChemFaces. B-caryophyllene and $\beta$-farnesene were purchased from SigmaAldrich.

\section{Quantification of Artemisinin by HPLC-ELSD}

The leaves of A. annua were collected, dried for $48 \mathrm{~h}$ at $50^{\circ} \mathrm{C}$ and ground into powder. One hundred milligrams of powder was extracted with $1 \mathrm{~mL}$ methanol for $30 \mathrm{~min}$ in an ultrasonic processor twice. The samples were centrifuged at $10,000 \mathrm{~g}$ for $10 \mathrm{~min}$. The supernatants were filtered through $0.25-\mu \mathrm{m}$-pore-size filters and analyzed by the Waters Alliance 2695 HPLC system coupled with a Waters 2420 ELSD detector (Milford, USA) (Zhang et al., 2009). Three biological repeats were measured for each sample.

\section{Functional Analysis of AaPDR3 in Yeast Cells}

AaPDR3 was cloned into the SpelI and PstI sites of pDR196 by In-Fusion PCR cloning kits (Clontech, Palo Alto, CA, USA). The recombinant plasmid was transformed the strain AD1234567833 by the lithium acetate method. The yeast transformant was incubated in $50 \mathrm{~mL} \mathrm{SD}$ medium (-uracil) at $29^{\circ} \mathrm{C}$ with shaking at $180 \mathrm{rpm}$, harvested at $\mathrm{A} 600=1.0$, and suspended by $50 \mathrm{~mL}$ half-strength SD medium (-uracil) containing $\beta$-caryophyllene, $\beta$-farnesene, and germacrene $\mathrm{D}$, respectively. The cells were cultivated at $29^{\circ} \mathrm{C}$ with shaking at $180 \mathrm{rpm}$, harvested at the indicated times by centrifugation, washed twice with sterile water. The cells were disrupted with acid-washed glass beads in methanol for $15 \mathrm{~min}$ at $30 \mathrm{~Hz}$ (Yu and De Luca, 2013). Yeast cells were incubated in the culture media in the range of $0-1,200$ $\mu \mathrm{M} \beta$-caryophyllene for $1.5 \mathrm{~h}$ at $\mathrm{pH}$ 5.9. The cells harvested at the indicated times by centrifugation, washed twice with sterile water. Samples were centrifuged and filtered for GC-MS analysis.

\section{RESULTS}

\section{Isolation and Characterization of AaPDR3}

Several studies have confirmed that many sesquiterpenes, with important biological functions, are produced in plant flower, leaf, secretory organ and root under constitutive, and stress conditions (Tholl, 2006). So we isolated T-shape trichomes from the capitulum of $A$. annua with laser capture microdissection and generated an RNA-Seq data based on
RNA isolated from T-shape trichomes. Based on the Tshape trichomes transcriptome databases, we identified the 88 putative $\mathrm{ABC}$ transporters by performing a BLASTP analysis using Arabidopsis ABC transporter protein sequences as queries (Supplementary Information Data 1). We performed the phylogenetic analysis between PDR subfamily transporters found in Arabidopsis thaliana and the putative ABC transporters from A. annua. The result showed that four proteins were clustered with PDR transporters from Arabidopsis thaliana, and four PDR proteins (contig012562, contig001446, contig009129, and contig004541) were clustered with PDR transporters from Arabidopsis (Figure 1). Subsequently, we performed a phylogenetic tree analysis with the predicted amino acid sequences of four candidate PDR proteins and some PDR transporters containing Arabidopsis PDR transporters, NpPDR1, NtPDR1 and SpTUR2, showing that contig004541 protein sequence was similar to that of PDR proteins (AtPDR12, NpPDR1, NtPDR1, and SpTUR2) involved in terpene transport (Figure 2A). Therefore, this gene, named AaPDR3, was further examined as the candidate gene. $A a P D R 3$, which is $4,278 \mathrm{bp}$ in length, encodes a protein of 1,425 amino acids. This protein, belonging to the full-length size PDR subfamily, contains two nucleotide-binding domains (NBD) and two transmembrane domains (TMD; Figure 2B). Compare the conserved domain of known PDR transporters involved in terpene transport exhibited the high conservation in plants (Figure 2C). Besides, we analyzed the expression of $A a P D R 3$ after the treatment with $100 \mu \mathrm{M} \mathrm{MeJA}$, showing that MeJA induced the expression of AaPDR3 in A. annua (Figure S2).

\section{Expression of AaPDR3 is Tissue-Specifically and Developmentally Regulated in A. annua}

Previous studies with CPS and BFS showed that the biosynthesis of related sesquiterpenes took place in roots, stems, leaves, and flower buds where they may play roles in defending the plant against fungal and worm attack (Lv et al., 2016). Consistent with these findings, investigation of $A a P D R 3$ transcript level by RTqPCR revealed that $A a P D R 3$ expression level was the highest in T-shaped trichomes (Figure 3A). AaPDR3 is also determined in roots, stems, leaves, and flower buds (Figure 3A). Moreover, we analyzed the expression of $A a P D R 3$ in leaves at different developmental stages. The expression level is the lowest in the youngest leaf (leaf0) and increased gradually with the leaves aging (Figure 3B).

\section{AaPDR3 Is Located to the Plasma Membrane}

Analysis of the encoded AaPDR3 protein by the subcellular prediction programs (Predotar: https://urgi. versailles.inra.fr/predotar/predotar.html; WoLF PSORT: http://www.genscript.com/psort/wolf_psort.html) predicted that this protein has no $\mathrm{N}$-terminal signal peptide and is located to the plasma membrane. To examine the subcellular localization of AaPDR3 protein, the green fluorescent protein (GFP) fused to the N-terminal domain of AaPDR3 under CaMV35S promoter 


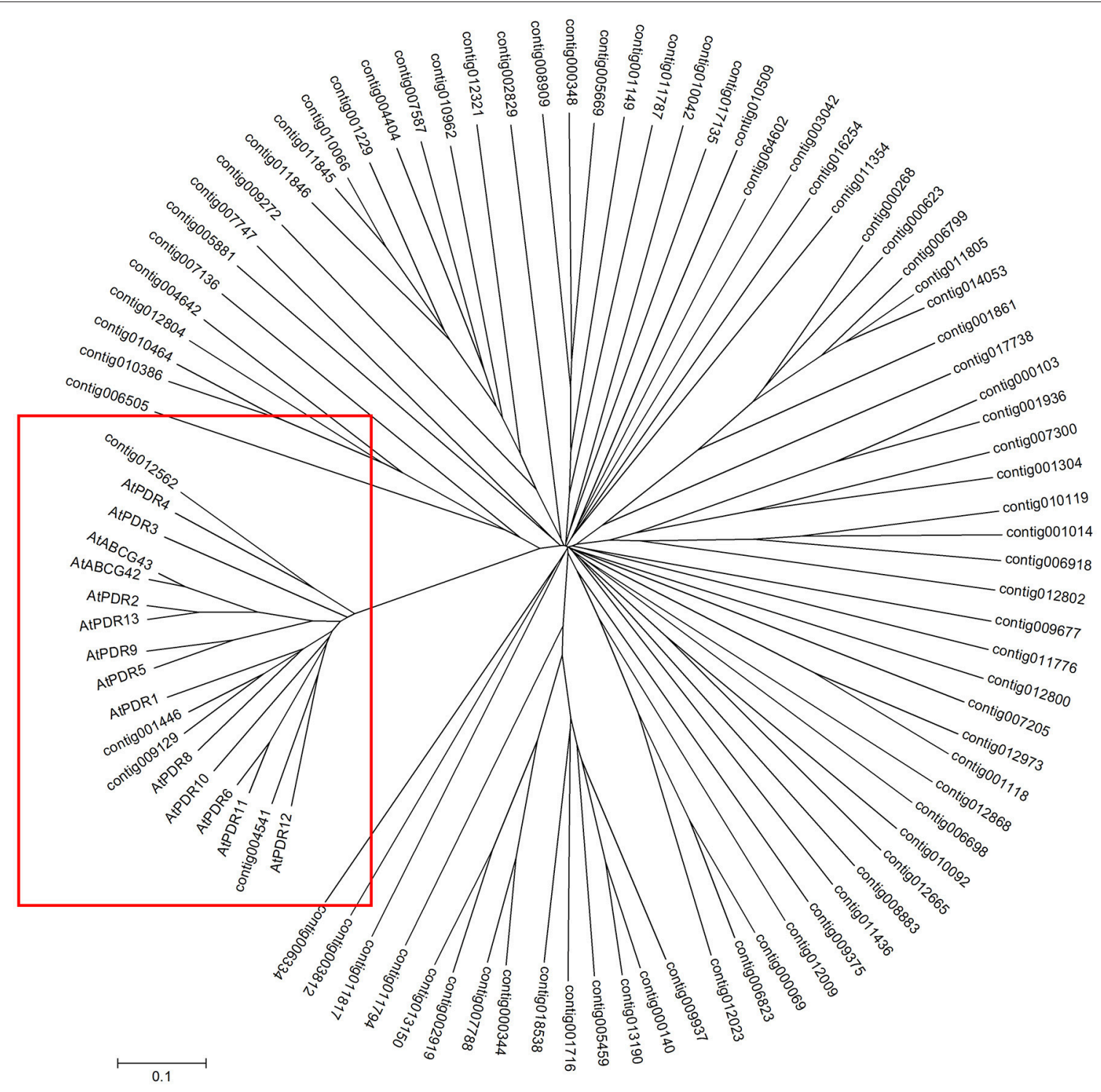

FIGURE 1 | Phylogenetic tree showing the relationship ABC transporters expressed in T-shape trichomes of $A$. annua compared with some PDR transporters from Arabidopsis. The tree presented here is a neighbor-joining tree based on amino acid sequence alignment.

was transiently expressed in tobacco leaves. Results showed that GFP fluorescence of leaves expressing GFP-AaPDR3 was only observed in the plasma membrane (Figure 4A). The GFP fused to the N-terminal domain of AaPDR3 together with the established plasma membrane marker PIP1 (Siefritz et al., 2002) fused to mCherry were transiently co-expressed in tobacco leaves. The GFP-AaPDR3 green fluorescent signal was colocalized to the plasma membrane with PIP1-mCherry (Figure 4B). The results were consistent with those from prediction programs, indicating that AaPDR3 was localized in the plasma membrane and might function as a transporter.

\section{AaPDR3 Is Expressed in T-Shaped Trichomes and Roots of $A$. annua}

To further investigate the tissue-specific expression pattern of AaPDR3 in A. annua, a 2,059-bp genomic fragment corresponding to the predicted AaPDR3 promoter sequence in our genome database was cloned from $A$. annua and then fused to GUS reporter gene. The recombinant plasmid was introduced into $A$. annua plants. GUS activity was analyzed in different tissues in A. annua. The result showed that GUSstaining was primarily restricted to T-shaped trichomes of old leaves in transgenic plants (Figures 5A-C). And GUS activity was also observed in roots in transgenic plants (Figure 5D), where a large number of sesquiterpenes are synthesized and stored.

\section{AaPDR3 Affects Sesquiterpenes $\beta$-Caryophyllene Biosynthesis in A. annua}

To explore the function of AaPDR3 in A. annua, we generated 34 AaPDR3-RNAi transgenic plants using an RNAi strategy under the control of the CaMV35S promoter. In the RNAi 
A

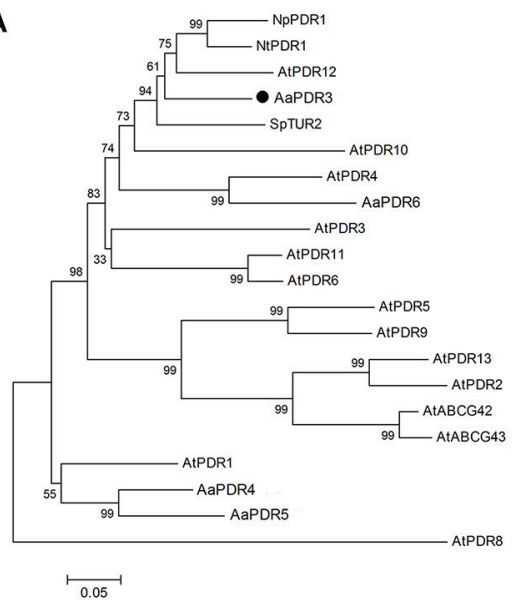

B

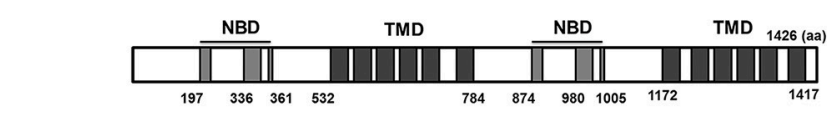

C

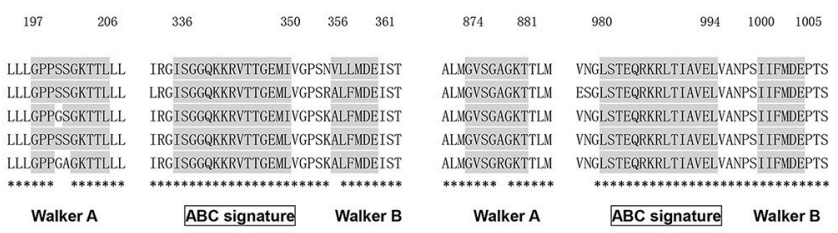

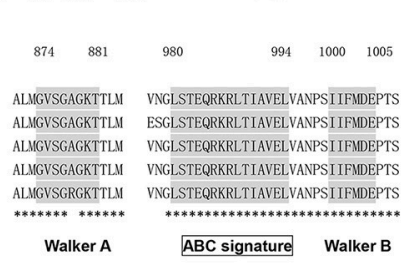

FIGURE 2 | Sequence analysis of AaPDR3. (A) Phylogenetic analysis of PDR proteins from A. annua and some known PDR transporters from Arabidopsis, N. plumbaginifolia NpPDR1, N. tabacum NtPDR1, and S. polyrrhiza SpTUR2. The tree presented here is a neighbor-joining tree based on amino acid sequence alignment. (B) The structure of AaPDR3 was predicted by scanning the deduced amino acid sequence. NBD and TMD indicate the predicted location of NBDs and TMDs, respectively. (C) Multiple alignment of the conserved domain of known PDR transporters involved in terpene transport has the high conservation in plants. The Walker A, Walker B, and ABC signature motifs are shown with shading. The identical amino acid residues in are marked by asterisks.
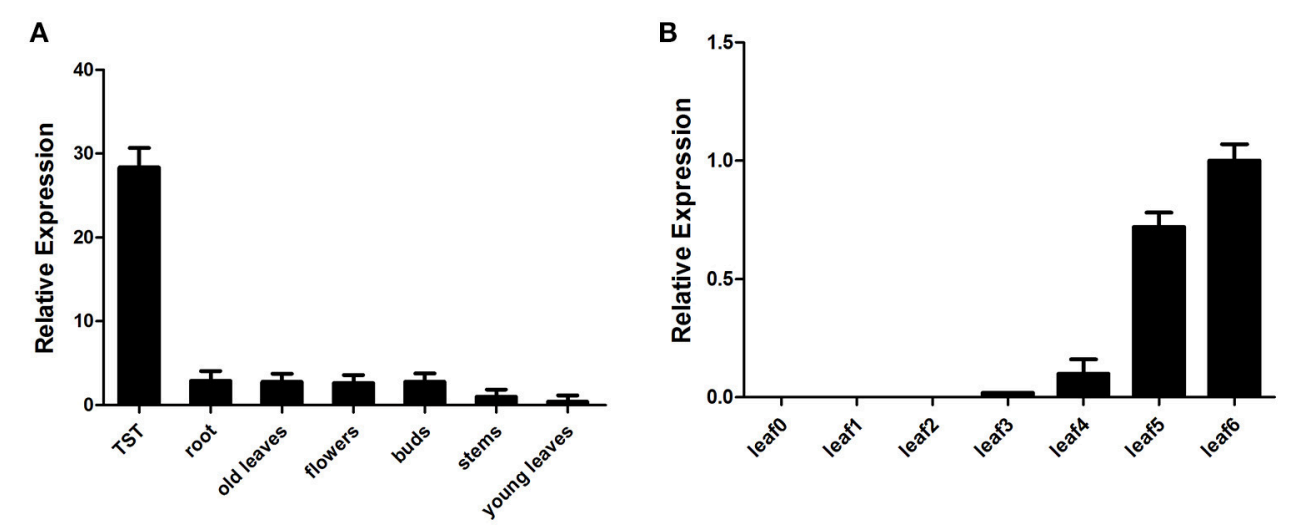

FIGURE 3 | Real-time PCR analysis for AaPDR3 expression. (A,B) Relative expression of AaPDR3 in (A) TST (T-shaped trichomes), roots, stems, old leaves, young leaves, buds, flowers, and (B) leaves of different developmental ages of $A$. annua. ACTIN was used as internal control. The error bars represent the means \pm $S D$ (standard deviation) from three technical replicates.

transgenic plants, four independent lines with $14-34 \%$ observably downregulated AaPDR3 expression (Figure 6A) were selected for the detailed metabolic profiling analysis by gas chromatography-mass spectrometry (GC-MS) analysis (Figure S3). In contrast with the wild type, the suppression of $A a P D R 3$ led to a $32-86 \%$ reduction of $\beta$ caryophyllene content (Figure 6B), while germacrene D and $\beta$-farnesene levels remained unchanged in AaPDR3$R N A i$ lines compared with wild type (Figure 6B). These data indicate that the repression of AaPDR3 markedly results in the suppression of sesquiterpene $\beta$-caryophyllene biosynthesis in $A$. aпnua.

AaPDR3 under the control of CaMV35S promoter was overexpressed in A. annua. We obtained 28 AaPDR3overexpressing transgenic plants. Investigation of $A a P D R 3$ transcript levels by qRT-PCR showed that the AaPDR3 expression was significantly increased in four AaPDR3overexpression lines (Figure 6C). The four independent transgenic lines were identified by Western blot (Figure S4). Consistent with a role involved in sesquiterpenes biosynthesis transport in planta, the level of $\beta$-caryophyllene was increased to $0.48 \mathrm{mg} / \mathrm{g} \mathrm{FW}$ in AaPDR3-overexpression lines compared to control $(0.28 \mathrm{mg} / \mathrm{g}$ FW; Figure 6D). Little increases of $\beta$-farnesene and germacrene $D$ were observed in AaPDR3-overexpression plants compared to wild type (Figure 6D). Taken together, AaPDR3 is involved in the sesquiterpene $\beta$-caryophyllene biosynthesis in $A$. annua. Moreover, the repression of AaPDR3 observably increased artemisinin contents in the RNAi plants (Figure S5). 
A

35S:GFP
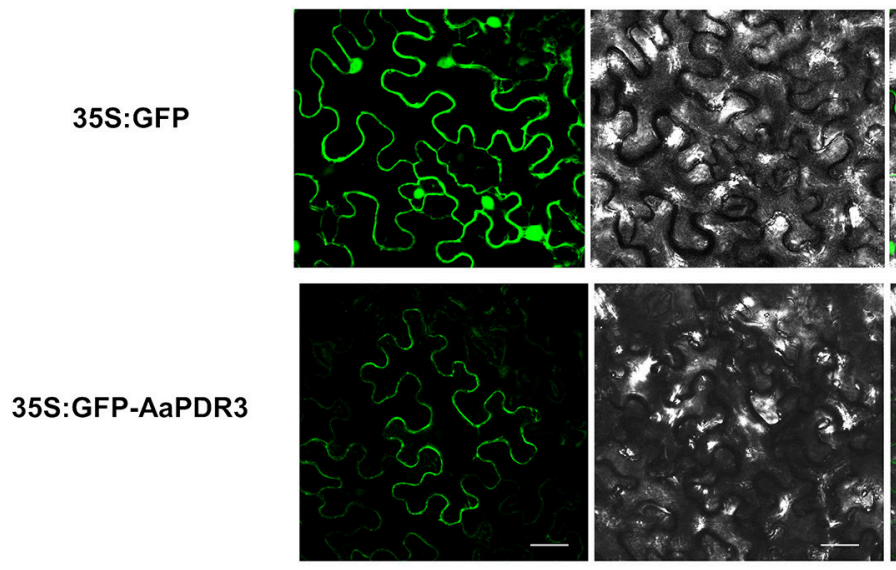

$\mathbf{B}$

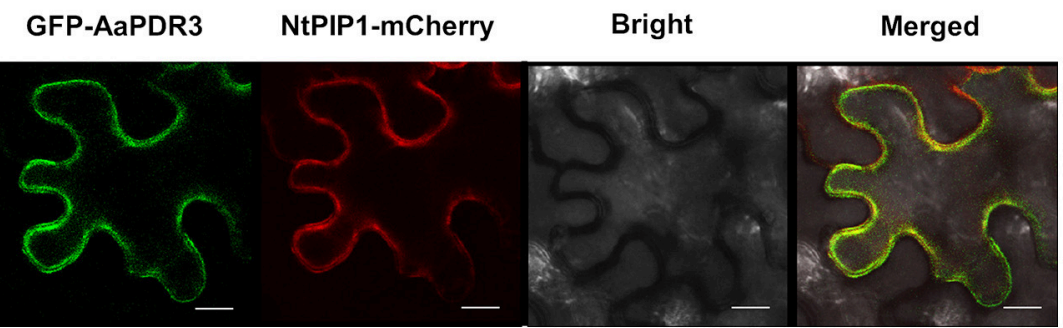

FIGURE 4 | The subcellular localization of AaPDR3. (A) Localization of AaPDR3 in tobacco leaves. Bars = $10 \mu \mathrm{m}$. (B) AaPDR3 protein co-localized with plasma membrane integral protein PIP1 on the plasma membrane of tobacco leaves determined through confocal microscopy. Bars $=40 \mu \mathrm{m}$.

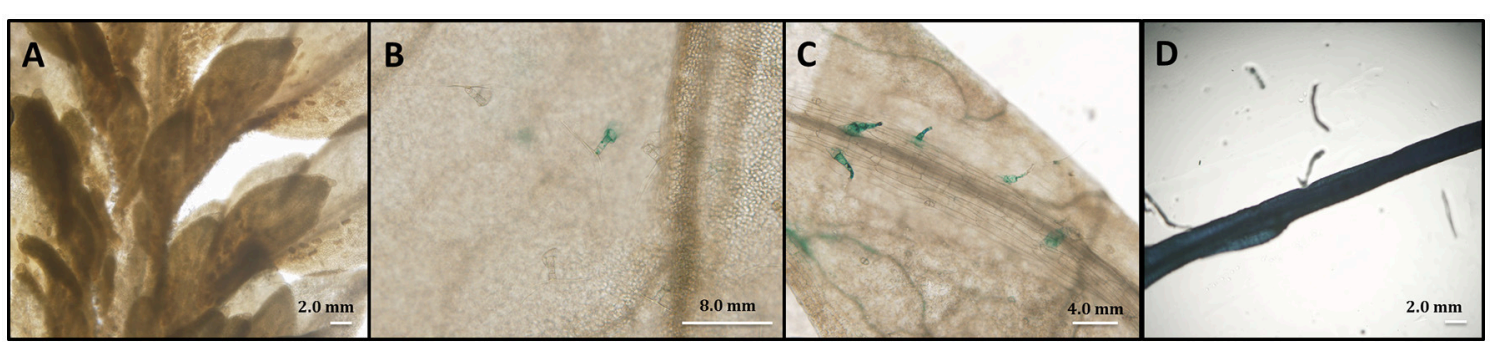

FIGURE $\mathbf{5}$ | AaPDR3 is mainly expressed in T-shape trichomes and roots. The expression of the proAaPDR3-GUS was observed in (A) the first leaf, (B) the fifth leaf, (C) the sixth leaf, and (D) the root.

\section{AaPDR3 Functions as $\beta$-Caryophyllene Transporter in Yeast Strain AD1-8}

A heterologous yeast expression system is an informative approach for elucidating the function of transporters (Morita et al., 2009; Shitan et al., 2013; Yu and De Luca, 2013). To investigate the function of AaPDR3 transporter, we expressed the AaPDR3 cDNA in the yeast strain AD12345678 lacking eight major $\mathrm{ABC}$ transporters and one transcription factor (Decottignies et al., 1998). Then we selected $\beta$-caryophyllene, $\beta$-farnesene, and germacrene $\mathrm{D}$ as the candidate substrates, respectively. The yeast cells of AaPDR 3 transformant and the control (transformed with the empty vector PDR196) were incubated in half-strength Synthetic Dextrose (SD) medium contained $100 \mu \mathrm{M}$ of each substrates, and the intracellular contents were quantitatively analyzed by LC-MS. Yeast cells expressing AaPDR3 accumulated more $\beta$-caryophyllene than the control along the same time course (Figure 7). The AaPDR3 transformants accumulated $>44 \mathrm{nmol}$ of $\beta$-caryophyllene per gram of cells compared with the control cells the contained almost $27 \mathrm{nmol}$ at $9 \mathrm{~h}$ treated by $100 \mu \mathrm{M} \beta$-caryophyllene (Figure 7). The result demonstrated that expression of AaPDR3 increased $\beta$-caryophyllene influx. Both AaPDR 3 transformants and the control were incubated in the culture media in the range of $0-1,200 \mu \mathrm{M} \beta$-caryophyllene. $\beta$-caryophyllene uptake by AaPDR3 followed Michaelis-Menten kinetics with $K_{m}$ of $63.47 \pm 8.81 \mathrm{pmol} \beta$-caryophyllene and a maximum transport 

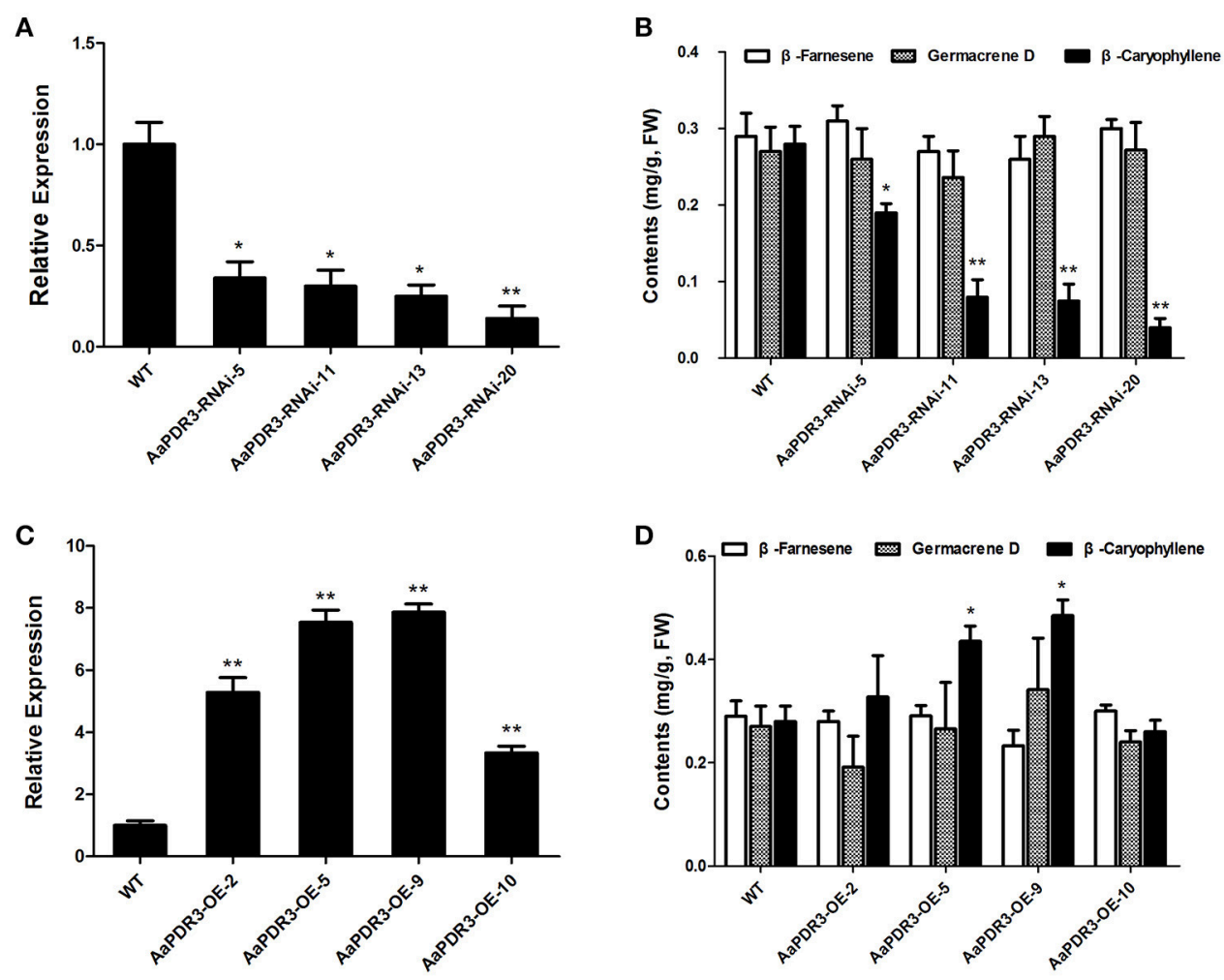

FIGURE 6 | Comparative analyses of AaPDR3 gene expression and sesquiterpene analyses in wild type (WT), in four AaPDR3-RNAi and four AaPDR3-overexpression plants. (A) Relative expression of $A a P D R 3$ in AaPDR3-RNAi transgenic $A$. annua lines. (B) The contents of $\beta$-farnesene, $\beta$-caryophyllene,

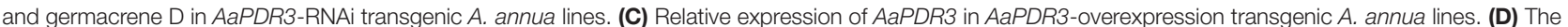
contents of $\beta$-farnesene, $\beta$-caryophyllene, and germacrene $D$ in $A a P D R 3$-overexpression transgenic $A$. annua lines. The error bars represent the means $\pm S D$ from three biological replicates, and asterisks indicate statistically significant differences compared with $\mathrm{WT}$. ${ }^{\star} P<0.05$, ${ }^{\star \star} P<0.01$.

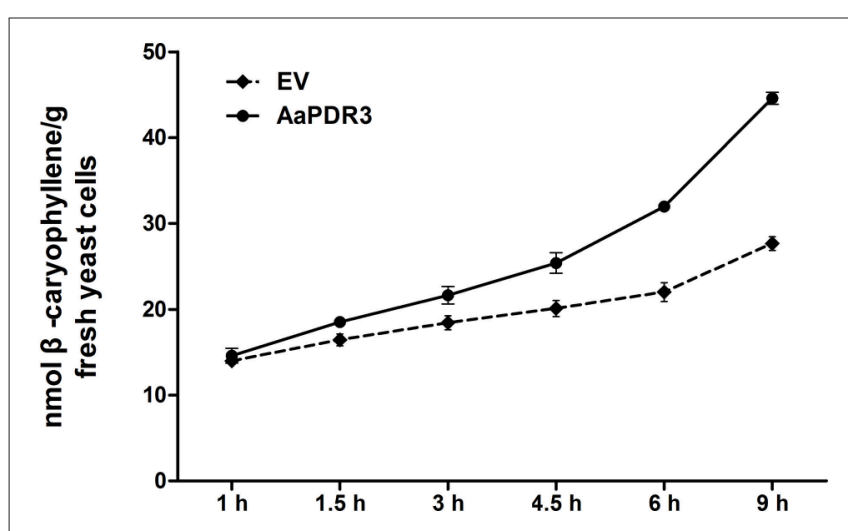

FIGURE 7 | Time-dependent uptake of $\beta$-caryophyllene by AD1-8 yeast cells expressing AaPDR3 and transformed with the empty vector (EV).

Yeast was incubated in half-strength SD medium containing $100 \mu \mathrm{M}$ $\beta$-caryophyllene at $\mathrm{pH}$ 5.9. The error bars represent the means $\pm S D$ from three biological replicates.

rate $V_{\max }$ of $80.89 \pm 2.46 \mathrm{pmol} / \mathrm{g}$ fresh yeast cells/min (Figure S6). No significant differences in the $\beta$-farnesene contents accumulated in AaPDR3 expressing yeast cells compared to that in the control group, as well as germacrene
D (Figure S7). These results indicated that AaPDR3 was highly specific for the $\beta$-caryophyllene transport compared with $\beta$-farnesene and germacrene $D$ in yeast.

\section{DISCUSSION}

\section{AaPDR3 Mediates the $\beta$-Caryophyllene Biosynthesis in A. annua}

The terpenoids are one of the largest groups of plant secondary metabolites (Croteau et al., 2000). Interestingly, the terpenoids are often transported from the cells where these compounds or metabolic intermediates are synthesized to neighboring cells, or even to other tissues or remote organs to be stored. Therefore, many transporter proteins participate in this biology process (Yazaki, 2005). Recently, the ATP-binding cassette $(\mathrm{ABC})$ transporters have been reported to largely contribute to membrane transport of terpenoids in plants, especially for PDR subfamily (Jasiński et al., 2001; Van Den Brûle et al., 2002; Crouzet et al., 2013). Most of identified PDR transporters were expressed in specific tissues. For example, AtPDR8 is predominately expressed in roots and leaves. AtPDR2, AtPDR6, AtPDR9, and AtPDR13 are exclusively expressed in roots but not in shoots in Arabidopsis, while AtPDR14 is expressed only in 
shoots (Den Brule and Smart, 2002). The expression of AtPDR5 is mainly detected in roots and stems (Bienert et al., 2012). NtABCG5/PDR5, from N. tabacum, was highly expressed in the petals, stem and roots (Bienert et al., 2012). NtPDR1 was detected in stem and leaf tissues (Crouzet et al., 2013). These findings show that $P D R$ genes are predominately expressed in roots and leaves. In plants, roots and leaves are the important tissues connected with environment. In this study, we characterized a PDR transporter AaPDR3 in A. annua. In our investigation, AaPDR3 was mainly active in old leaves, flowers, buds, and roots (Figure 3A). Notably, the GUS analysis exhibited that AaPDR3 was specifically expressed in T-shaped trichomes of old leaves and roots (Figure 5C). Likewise, AaPDR3 exhibited the tissues-specific expression pattern, suggesting that AaPDR3 plays an important role in the defensive compounds biosynthesis in T-shaped trichomes, flowers, buds, and roots. Moreover, the transcript level of CPS was also detected in leaves, flowers, buds, and roots (Lv et al., 2016), which is in accord with that of AaPDR3 in A. annua. Besides, the expression level of AaPDR3 was barely detected in the youngest leaf (leaf0), and increased gradually with the leaves aging (Figure 3B). Although the expression of CPS was highest in youngest leaf (leaf0), the CPS transcript level was also detected with the leaves aging ( $\mathrm{Lv}$ et al., 2016). It means that $\beta$ caryophyllene is synthesized in young leaves and old leaves. From these results, we propose that AaPDR3 as a plasma membrane $\beta$-caryophyllene cellular uptake for gathering $\beta$-caryophyllene. Then the gathered $\beta$-caryophyllene is stored in the some cells of T-shape trichomes to reduce the cell damaged.

To identify the function of AaPDR3 in A. annua, we used RNAi to knock down the expression of AaPDR3. The repression of $A a P D R 3$ resulted in an $86 \%$ reduction of $\beta$ caryophyllene content in AaPDR3-RNAi-20 transgenic A. annua line (Figure 6B), suggesting that AaPDR3 is essential for $\beta$ caryophyllene biosynthesis in A. annua. Transporters are the integral parts in metabolic networks, because they mediate multiple metabolic pathways. We speculated that the AaPDR3 repression would result in $\beta$-caryophyllene accumulated in the cells of T-shape trichomes in A. annua, which would prevent the $\beta$-caryophyllene biosynthesis. Our results, together with previous findings, indicated that AaPDR3 is involved in $\beta$-caryophyllene transport and plays an indispensable role in $\beta$-caryophyllene biosynthesis. AaPDR3 transporter reported here is the first transporter related to sesquiterpenes in A. annua, even in family Asteraceae.

\section{AaPDR3 Was Involved in $\beta$-Caryophyllene Transport in Yeast}

Plant $\mathrm{ABC}$ transporters is a large and diverse group of proteins involved in the pathogen response, lipid deposition, and the transport of the phytohormones (Kretzschmar et al., 2011). Therefore, $\mathrm{ABC}$ transporters play an important part in plant growth, nutrition, development, and the interaction with the environment (Bird et al., 2007; Kuromori et al., 2010; Ding et al., 2011). Our results preferentially suggest that AaPDR3 is likely to be involved in the sesquiterpene $\beta$-caryophyllene transport based on four findings: (i) like other sesquiterpene transporters; the amino acid sequence of AaPDR3 is similar to that of PDR transporters involved in terpene transport
(Figure 2A), (ii) the plasma membrane protein AaPDR3 is expressed in the tissues, including the T-shaped trichomes, buds, flowers, and roots, where the sesquiterpenes are synthesized (Figure 3A), (iii) increase and decrease in the AaPDR3 transcript level influence the sesquiterpene $\beta$-caryophyllene biosynthesis (Figure 6), and (iv) when $A a P D R 3$ was expressed in yeast mutant AD1-8, yeast expressing AaPDR3 only took up $\beta$-caryophyllene faster than controls containing the empty vector (Figure 7). In fact, some $\mathrm{ABC}$ transporters are reported to have broad substrate specificity (Kolaczkowski et al., 1998). For example, PDR5 transporter from yeast was confirmed to export some compounds which had different structure and function (Wolfger et al., 2001; Lamping et al., 2010). In Arabidopsis, AtPDR12 is an ABA-uptake transporter in the guard cells and other cells (Kang et al., 2010). The plasma membrane transporter, AtPDR12, also contributes to the resistance of lead (Lee et al., 2005). When the yeast cells expressing AaPDR3 was incubated in SD medium contained $100 \mu \mathrm{M} \beta$-caryophyllene, $\beta$-farnesene, and germacrene $\mathrm{D}$, respectively, our results showed that AaPDR3 exhibited narrow substrate specificity (Figure 7 and Figure S6).

\section{AaPDR3 Affects the Artemisinin Biosynthesis in A. annua}

Amazingly, we found that knockdown of $A a P D R 3$ resulted in an increase in artemisinin content in AaPDR3-RNAi transgenic plants (Figure S5). AaPDR3 is a specific-expressed transporter gene in T-shape trichomes (Figure 4C), whereas artemisinin is specially synthesized in glandular trichomes. As we known, blocking the competitive pathways of artemisinin biosynthesis is very useful to improve the artemisinin content (Zhang et al., 2009; Lv et al., 2016). Both the artemisinin and dihydroartemisinic acid contents were increased, when CPS was suppressed by anti-sense in A. annua (Lv et al., 2016). The $\beta$ caryophyllene content in $A$. annua was up to $5-10 \%$ of the total essential oil (Brown, 2010). When AaPDR3 was downregulated by RNAi in $A$. annua, the $\beta$-caryophyllene content was observably reduced in transgenic plants (Figure 6B), which might lead to the carbon altered through FPP to artemisinin biosynthetic pathway.

\section{ACCESSION NUMBERS}

AaPDR3 (KR153482), AtPDR1 (NM_112505.4), AtPDR2 (NM_117611.5), AtPDR3 (NM_128548.4), AtPDR4 (NM_128 248.2), AtPDR5 (NM_001336647.1), AtPDR6 (NM_129195.6), AtPDR7 (NM_101389.3), AtPDR8 (GQ374243.1), AtPDR9 (NM_115208.4), AtPDR10 (NM_001339062.1), AtPDR11 (NM_105366.4), AtPDR12 (NM_001332173.1), AtPDR13 (NM_001341001.1), AtABCG42 (NM_001203808.2), AtABCG43 (NM_148328.3), NpPDR1 (Q949G3.1), NtPDR1 (Q76CU2.1), SpTUR2 (O24367.1).

\section{AUTHOR CONTRIBUTIONS}

$\mathrm{XF}$ and KT designed the research and drafted the manuscript. $\mathrm{XF}$ and PS performed the experiments. XF, QH, QS, YM, and PL carried out vector construct, expression analysis, transgene plant 
generation, subcellular localization and yeast assay. YT, QP, TY, MC, XH, LL, YW, and XS revised the manuscript. All authors approved the manuscript.

\section{FUNDING}

This work was supported by the China National Transgenic Plant Research and Commercialization Project (Grant No. 2016ZX08002-001), China National High Technology Research and Development Program (Grant No. 2011AA100605), and Shanghai Jiao Tong University Agri-Engineering Program (Grant No. AF1500028).

\section{ACKNOWLEDGMENTS}

We thank Prof. Masakazu Niimi (Otago University, New Zealand), Prof. André Goffeau (Université Catholique de Louvain, Belgium), and Prof. Mohan Gupta (Chicago University, USA) for providing the yeast AD12345678 strain. We thank the Instrumental Analysis Center of the Shanghai Jiao Tong University for assistance with GC-MS.

\section{SUPPLEMENTARY MATERIAL}

The Supplementary Material for this article can be found online at: http://journal.frontiersin.org/article/10.3389/fpls.2017. 00723/full\#supplementary-material

Figure S1 | The sesquiterpene biosynthesis in Artemisia annua. HMGR,

3-hydroxy-3- methylglutaryl coenzyme A reductase; DXS,

1-deoxy-D-xylulose-5-phosphate synthase; DXR, 1-deoxy-D-xylulose

5-phosphate reductase. FPS, farnesyl diphosphate; ADS, amorpha-4,11-diene

\section{REFERENCES}

Bertea, C. M., Voster, A., Verstappen, F. W., Maffei, M., Beekwilder, J., and Bouwmeester, H. J. (2006). Isoprenoid biosynthesis in Artemisia annua: cloning and heterologous expression of a germacrene A synthase from a glandular trichome cDNA library. Arch. Biochem. Biophys. 448, 3-12. doi: 10.1016/j.abb.2006.02.026

Bessire, M., Borel, S., Fabre, G., Carraca, L., Efremova, N., Yephremov, A., et al. (2011). A member of the PLEIOTROPIC DRUG RESISTANCE family of atp binding cassette transporters is required for the formation of a functional cuticle in Arabidopsis. Plant Cell 23, 1958-1970. doi: 10.1105/tpc.111.083121

Bhakuni, R. S., Jain, D. C., Sharma, R. P., and Kumar, S. (2001). Secondary metabolites of Artemisia annua and their biological activity. Curr. Sci. 80, $35-48$.

Biemansoldehinkel, E., Doeven, M. K., and Poolman, B. (2006). ABC transporter architecture and regulatory roles of accessory domains. FEBS Lett. 580, 1023-1035. doi: 10.1016/j.febslet.2005.11.079

Bienert, M. D., Siegmund, S. E. G., Drozak, A., Trombik, T., Bultreys, A., Baldwin, I. T., et al. (2012). A pleiotropic drug resistance transporter in Nicotiana tabacum is involved in defense against the herbivore Manduca sexta. Plant J. 72, 745-757. doi: 10.1111/j.1365-313X.2012.05108.x

Bird, D., Beisson, F., Brigham, A., Shin, J., Greer, S., Jetter, R., et al. (2007). Characterization of Arabidopsis ABCG11/WBC11, an ATP binding cassette $(\mathrm{ABC})$ transporter that is required for cuticular lipid secretion. Plant J. 52, 485-498. doi: 10.1111/j.1365-313X.2007.03252.x

Bouwmeester, H. J., Wallaart, T. E., Janssen, M. H., van Loo, B., Jansen, B. J., Posthumus, M. A., et al. (1999). Amorpha-4, 11-diene synthase catalyses the synthase; CPR, cytochrome P450 reductase; CYP71AV1, cytochrome P450 monooxygenase; DBR2, artemisinic aldehyde D-11(13)-double bond reductase; ALDH1, aldehyde dehydrogenase 1; CYB5 and ADH1, cytochrome b5 monooxygenase and alcohol dehydrogenase. CPS, beta-caryophyllene synthase; BFS, beta-farnesene synthase; GAS, germacrene A synthase; ECS, 8-epicedrol synthase.

Figure S2 | The expression of AaPDR3 was induced by MeJA treatment. $A C T I N$ was used as internal control. The error bars represent the means $\pm S D$ from three biological replicates.

Figure S3 | Total ion chromatographs of metabolites from leaves of A. annua.

Figure S4 | Immunoblotting analysis of GFP-AaPDR3 protein levels in AaPDR3-overexpression transgenic $A$. annua lines.

Figure S5 | The content of artemisinin in overexpression and RNAi transgenic $\boldsymbol{A}$. annua plants, respectively. The error bars represent the means $\pm \mathrm{SD}$ from three biological replicates, and asterisks indicate statistically significant differences compared with WT. ${ }^{* *} P<0.01$.

Figure S6 | $\beta$-caryophyllene uptake analyses by AD1-8 yeast cells expressing AaPDR3 and transformed with the empty vector (EV). Yeast cells were incubated in the culture media in the range of $0-1,200 \mu \mathrm{M}$ $\beta$-caryophyllene at $\mathrm{pH}$ 5.9. $\beta$-caryophyllene uptake by AaPDR3 followed MichaelisMenten kinetics with $\mathrm{K}_{\mathrm{m}}$ of $63.47 \pm 8.81 \mathrm{pmol} \beta$-caryophyllene and a maximum transport rate $V_{\max }$ of $80.89 \pm 2.46 \mathrm{pmol} / \mathrm{g}$ fresh yeast cells $/ \mathrm{min}\left(R^{2}=0.98\right)$. The error bars represent the means $\pm S D$ from three biological replicates.

Figure S7 | Time-dependent uptake of (A) $\beta$-farnesene and (B) germacrene D by AD1-8 yeast cells expressing AaPDR3 and transformed with the empty vector (EV). Yeast was incubated in half-strength SD medium containing $100 \mu \mathrm{m}$ $\beta$-farnesene and germacrene $\mathrm{D}$ at $\mathrm{pH} 5.9$, respectively. The error bars represent the means $\pm S D$ from three biological replicates.

Table S1 | Primers used in this study.

Supplementary Information Data 1 | Four selected PDR genes in transcriptome expression in glandular and T-shaped trichomes.

first probable step in artemisinin biosynthesis. Phytochemistry 52, 843-854. doi: 10.1016/S0031-9422(99)00206-X

Bowers, W. S., Nault, L. R., Webb, R. E., and Dutky, S. R. (1972). Aphid alarm pheromone: isolation, identification, synthesis. Science 177, 1121-1122. doi: $10.1126 /$ science.177.4054.1121

Brown, G. D. (2010). The biosynthesis of artemisinin (Qinghaosu) and the phytochemistry of Artemisia annua L. (Qinghao). Molecules 15, 7603-7698. doi: $10.3390 /$ molecules 15117603

Cai, Y., Jia, J. W., Crock, J., Lin, Z. X., Chen, X. Y., and Croteau, R. (2002). A cDNA clone for $\beta$-caryophyllene synthase from Artemisia annua. Phytochemistry 61, 523-529. doi: 10.1016/S0031-9422(02)00265-0

Cakir, B., and Kilickaya, O. (2013). Whole-genome survey of the putative ATPbinding cassette transporter family genes in Vitis vinifera. PLoS ONE 8:e78860. doi: 10.1371/journal.pone.0078860

Charles, D. J., Cebert, E., and Simon, J. E. (1991). Characterization of the essential oil of Artemisia annua L. J. Essent. Oil Res. 3, 33-39. doi: 10.1080/10412905.1991.9697903

Croteau, R., Kutchan, T. M., and Lewis, N. G. (2000). "Chapter 24: Natural products (secondary metabolites)," in Biochemistry and Molecular Biology of Plants, eds B. Buchanan, W. Gruissem, and R. Jones (Rockville, MD: American Society of Plant Physiologists), 1250-1319.

Crouzet, J., Roland, J., Peeters, E., Trombik, T., Ducos, E., Nader, J., et al. (2013). NtPDR1, a plasma membrane ABC transporter from Nicotiana tabacum, is involved in diterpene transport. Plant Mol. Biol. 82, 181-192. doi: 10.1007/s11103-013-0053-0

Decottignies, A., Grant, A. M., Nichols, J. W., de Wet, H., McIntosh, D. B., and Goffeau, A. (1998). ATPase and multidrug transport activities of the 
overexpressed yeast ABC protein Yorlp. J. Biol. Chem. 273, 12612-12622. doi: $10.1074 /$ jbc.273.20.12612

Degenhardt, J., Gershenzon, J., Baldwin, I. T., and Kessler, A. (2003). Attracting friends to feast on foes: engineering terpene emission to make crop plants more attractive to herbivore enemies. Curr. Opin. Biotechnol. 14, 169-176. doi: 10.1016/S0958-1669(03)00025-9

Den Brule, S. V., and Smart, C. C. (2002). The plant PDR family of ABC transporters. Planta 216, 95-106. doi: 10.1007/s00425-002-0889-Z

Ding, Z., Galván-Ampudia, C. S., Demarsy, E., Langowski, L., Kleine-Vehn, J., Fan, Y., et al. (2011). Light-mediated polarization of the PIN3 auxin transporter for the phototropic response in Arabidopsis. Nat. Cell Biol. 13, 447-452. doi: $10.1038 / \mathrm{ncb} 2208$

Duke, S. O., and Paul, R. N. (1993). Development and fine structure of the glandular trichomes of Artemisia annua L. Int. J. Plant Sci. 154, 107-118. doi: $10.1086 / 297096$

Francis, F., Lognay, G., and Haubruge, E. (2004). Olfactory responses to aphid and host plant volatile releases:(E)- $\beta$-farnesene an effective kairomone for the predator Adalia bipunctata. J. Chem. Ecol. 30, 741-755. doi: 10.1023/B:JOEC.0000028429.13413.a2

Fulzele, D. P., Heble, M., and Rao, P. (1995). Production of terpenoid from Artemisia annua L. plantlet cultures in bioreactor. J. Biotechnol. 40,139-143. doi: 10.1016/0168-1656(95)00034-N

Goel, D., Singh, V., Ali, M., Mallavarupu, G. R., and Kumar, S. (2007). Essential oils of petal, leaf and stem of the antimalarial plant Artemisia annua. J. Nat. Med. 61, 187-191. doi: 10.1007/s11418-006-0112-9

Holm, Y., Laakso, I., Hiltunen, R., and Galambosi, B. (1997). Variation in the essential oil composition of Artemisia annua L. of different origin cultivated in Finland. Flavour Frag. J. 12, 241-246. doi: 10.1002/(SICI)1099-1026(199707)12:4<241::AID-FFJ641>3.0.CO;2-Z

Ito, H., and Gray, W. M. (2006). A gain-of-function mutation in the Arabidopsis pleiotropic drug resistance transporter PDR9 confers resistance to auxinic herbicides. Plant Physiol. 142, 63-74. doi: 10.1104/pp.106.084533

Jasiński, M., Stukkens, Y., Degand, H., Purnelle, B., Marchand-Brynaert, J., and Boutry, M. (2001). A plant plasma membrane ATP binding cassettetype transporter is involved in antifungal terpenoid secretion. Plant Cell 13, 1095-1107. doi: 10.1105/tpc.13.5.1095

Jefferson, R. A. (1987). Assaying chimeric genes in plants: the GUS gene fusion system. Plant Mol. Biol. Rep. 5, 387-405. doi: 10.1007/BF02667740

Jia, J. W., Crock, J., Lu, S., Croteau, R., and Chen, X. Y. (1999). (3R)-Linalool synthase from Artemisia annua L.: cDNA isolation, characterization, and wound induction. Arch. Biochem. Biophys. 372, 143-149. doi: 10.1006/abbi.1999.1466

Juteau, F., Masotti, V., Bessiere, J. M., Dherbomez, M., and Viano, J. (2002). Antibacterial and antioxidant activities of Artemisia annua essential oil. Fitoterapia 73, 532-535. doi: 10.1016/S0367-326X(02)00175-2

Kang, J., Hwang, J. U., Lee, M., Kim, Y. Y., Assmann, S. M., Martinoia, E., et al. (2010). PDR-type ABC transporter mediates cellular uptake of the phytohormone abscisic acid. Pro. Natl. Acad. Sci. U.S.A. 107, 2355-2360. doi: 10.1073/pnas.0909222107

Kim, D. Y., Bovet, L., Maeshima, M., Martinoia, E., and Lee, Y. (2007). The ABC transporter AtPDR8 is a cadmium extrusion pump conferring heavy metal resistance. Plant J. 50, 207-218. doi: 10.1111/j.1365-313X.2007.03044.x

Kim, D. Y., Jin, J. Y., Alejandro, S., Martinoia, E., and Lee, Y. (2010). Overexpression of AtABCG36 improves drought and salt stress resistance in Arabidopsis. Physiol. Plant. 139, 170-180. doi: 10.1111/j.1399-3054.2010.01353.x

Kobae, Y., Sekino, T., Yoshioka, H., Nakagawa, T., Martinoia, E., and Maeshima, M. (2006). Loss of AtPDR8, a plasma membrane ABC transporter of Arabidopsis thaliana, causes hypersensitive cell death upon pathogen infection. Plant Cell Physiol. 47, 309-318. doi: 10.1093/pcp/pcj001

Kolaczkowski, M., Kolaczkowska, A., Luczynski, J., Witek, S., and Goffeau, A. (1998). In vivo characterization of the drug resistance profile of the major ABC transporters and other components of the yeast pleiotropic drug resistance network. Microb. Drug Resist. 4, 143-158. doi: 10.1089/mdr.1998.4.143

Kretzschmar, T., Burla, B., Lee, Y., Martinoia, E., and Nagy, R. (2011). Functions of ABC transporters in plants. Essays Biochem. 50, 145-160. doi: $10.1042 /$ bse0500145
Kuromori, T., Miyaji, T., Yabuuchi, H., Shimizu, H., Sugimoto, E., Kamiya, A., et al. (2010). ABC transporter AtABCG25 is involved in abscisic acid transport and responses. Pro. Natl. Acad. Sci. U.S.A. 107, 2361-2366. doi: 10.1073/pnas.0912516107

Lamping, E., Baret, P. V., Holmes, A. R., Monk, B. C., Goffeau, A., and Cannon, R. D. (2010). Fungal PDR transporters: phylogeny, topology, motifs and function. Fungal Genet. Biol. 47, 127-142. doi: 10.1016/j.fgb.2009.10.007

Lanphear, B. P. (1998). The paradox of lead poisoning prevention. Science 281, 1617-1618. doi: 10.1126/science.281.5383.1617

Lee, M., Lee, K., Lee, J., Noh, E. W., and Lee, Y. (2005). AtPDR12 contributes to lead resistance in Arabidopsis. Plant Physiol. 138, 827-836. doi: $10.1104 / \mathrm{pp} .104 .058107$

Legault, J., and Pichette, A. (2007). Potentiating effect of $\beta$-caryophyllene on anticancer activity of $\alpha$-humulene, isocaryophyllene and paclitaxel. J. Pharm. Pharmacol. 59, 1643-1647. doi: 10.1211/jpp.59.12.0005

Liu, Y., Ye, H. C., Wang, H., and Li, G. F. (2003). Molecular cloning, Escherichia coli expression and genomic organization of squalene synthase gene from Artemisia annua. Acta Bot. Sin. 45, 608-613.

Lv, Z. Y., Zhang, F. Y., Pan, Q. F., Fu, X. Q., Jiang, W. M., Shen, Q., et al. (2016). Branch pathway blocking in Artemisia annua is a useful method for obtaining high yield artemisinin. Plant Cell Physiol. 57, 588-602. doi: $10.1093 / \mathrm{pcp} / \mathrm{pcw} 014$

Mercke, P., Crock, J., Croteau, R., and Brodelius, P. E. (1999). Cloning, expression, and characterization of epi-cedrol synthase, a sesquiterpene cyclase from Artemisia annua L. Arch. Biochem. Biophys. 369, 213-222. doi: 10.1006/abbi.1999.1358

Morita, M., Shitan, N., Sawada, K., Van Montagu, M. C., Inzé, D., Rischer, H., et al. (2009). Vacuolar transport of nicotine is mediated by a multidrug and toxic compound extrusion (MATE) transporter in Nicotiana tabacum. Pro. Natl. Acad. Sci. U.S.A. 106, 2447-2452. doi: 10.1073/pnas.0812512106

Olsson, M. E., Olofsson, L. M., Lindahl, A. L., Lundgren, A., Brodelius, M., and Brodelius, P. E. (2009). Localization of enzymes of artemisinin biosynthesis to the apical cells of glandular secretory trichomes of Artemisia annua L. Phytochemistry 70, 1123-1128. doi: 10.1016/j.phytochem.2009.07.009

Picaud, S., Brodelius, M., and Brodelius, P. E. (2005). Expression, purification and characterization of recombinant (E)- $\beta$-farnesene synthase from Artemisia annua. Phytochemistry 66, 961-967. doi: 10.1016/j.phytochem.2005.03.027

Pichersky, E., and Gershenzon, J. (2002). The formation and function of plant volatiles: perfumes for pollinator attraction and defense. Curr. Opin. Plant Biol. 5, 237-243. doi: 10.1016/S1369-5266(02)00251-0

Pickett, J. A., and Griffiths, D. C. (1980). Composition of aphid alarm pheromones. J. Chem. Ecol. 6, 349-360. doi: 10.1007/BF01402913

Raskin, I. I., Smith, R. D., and Salt, D. E. (1997). Phytoremediation of metals: using plants to remove pollutants from the environment. Curr. Opin. Plant Biol. 8, 221-226. doi: 10.1016/s0958-1669(97)80106-1

Shitan, N., Dalmas, F., Dan, K., Kato, N., Ueda, K., Sato, F., et al. (2013). Characterization of Coptis japonica CjABCB2, an ATP-binding cassette protein involved in alkaloid transport. Phytochemistry 91, 109-116. doi: 10.1016/j.phytochem.2012.02.012

Siefritz, F., Tyree, M. T., Lovisolo, C., Schubert, A., and Kaldenhoff, R. (2002). PIP1 plasma membrane aquaporins in tobacco: from cellular effects to function in plants. Plant Cell 14, 869-876. doi: 10.1105/tpc.000901

Smart, C. C., and Fleming, A. J. (1996). Hormonal and environmental regulation of a plant PDR5-like ABC transporter. J. Biol. Chem. 271, 19351-19357. doi: 10.1074/jbc.271.32.19351

Soetaert, S. S., Neste, C. M. V., Vandewoestyne, M. L., Head, S. R., Goossens, A., Nieuwerburgh, F. C. V., et al. (2013). Differential transcriptome analysis of glandular and filamentous trichomes in Artemisia annua. BMC Plant Biol. 13:220. doi: 10.1186/1471-2229-13-220

Strader, L. C., and Bartel, B. (2009). The Arabidopsis PLEIOTROPIC DRUG RESISTANCE8/ABCG36 ATP binding cassette transporter modulates sensitivity to the auxin precursor indole-3-butyric acid. Plant Cell 21, 1992-2007. doi: 10.1105/tpc.109.065821

Stukkens, Y., Bultreys, A., Grec, S., Trombik, T., Vanham, D., and Boutry, M. (2005). NpPDR1, a pleiotropic drug resistance-type ATP-binding cassette transporter from Nicotiana plumbaginifolia, plays a major role in plant pathogen defense. Plant Physiol. 139, 341-352. doi: 10.1104/pp.105.062372 
Sugiyama, A., Shitan, N., Sato, S., Nakamura, Y., Tabata, S., and Yazaki, K. (2006). Genome-wide analysis of ATP-binding cassette $(\mathrm{ABC})$ proteins in a model legume plant, Lotus japonicus: comparison with Arabidopsis $\mathrm{ABC}$ protein family. DNA Res. 13, 205-228. doi: 10.1093/dnares/dsl013

Tamura, K., Peterson, D., Peterson, N., Stecher, G., Nei, M., and Kumar, S. (2011). MEGA5: molecular evolutionary genetics analysis using maximum likelihood, evolutionary distance, and maximum parsimony methods. Mol. Biol. Evol. 28, 2731-2739. doi: 10.1093/molbev/msr121

Tellez, M. R., Canel, C., Rimando, A. M., and Duke, S. O. (1999). Differential accumulation of isoprenoids in glanded and glandless Artemisia annua L. Phytochemistry 52, 1035-1040. doi: 10.1016/S0031-9422(99)00308-8

Tholl, D. (2006). Terpene synthases and the regulation, diversity and biological roles of terpene metabolism. Curr. Opin. Plant Biol. 9, 297-304. doi: 10.1016/j.pbi.2006.03.014

Van Den Brûle, S., Müller, A., Fleming, A. J., and Smart, C. C. (2002). The ABC transporter SpTUR2 confers resistance to the antifungal diterpene sclareol. Plant J. 30, 649-662. doi: 10.1046/j.1365-313X.2002.01321.x

Verrier, P. J., Bird, D., Burla, B., Dassa, E., Forestier, C., Geisler, M., et al. (2008). Plant ABC proteins-a unified nomenclature and updated inventory. Trends Plant Sci. 13, 151-159. doi: 10.1016/j.tplants.2008.02.001

Voinnet, O., Rivas, S., Mestre, P. and Baulcombe, D. (2003). An enhanced transient expression system in plants based on suppression of gene silencing by the p19 protein of tomato bushy stunt virus. Plant J. 33, 949-956. doi: 10.1046/j.1365-313X.2003.01676.x

Wagner, G. J. (1991). Secreting glandular trichomes: more than just hairs. Plant Physiol. 96, 675-679. doi: 10.1104/pp.96.3.675

Wang, B., Kashkooli, A. B., Sallets, A., Ting, H. M., de Ruijter, N. C., Olofsson, L., et al. (2016). Transient production of artemisinin in Nicotiana benthamiana is boosted by a specific lipid transfer protein from A. annua. Metab. Eng. 38, 159-169. doi: 10.1016/j.ymben.2016.07.004

Wang, H., Han, J., Kanagarajan, S., Lundgren, A., and Brodelius, P. E. (2013). Studies on the expression of sesquiterpene synthases using promoter-betaglucuronidase fusions in transgenic Artemisia annua L. PLoS ONE 8:e80643. doi: 10.1371/journal.pone.0080643

Wang, H., Kanagarajan, S., Han, J., Hao, M., Yang, Y., Lundgren, A., et al. (2014). Studies on the expression of linalool synthase using a promoter-betaglucuronidase fusion in transgenic Artemisia annua. J. Plant Physiol. 171, 85-96. doi: 10.1016/j.jplph.2013.09.019
Wei, Z. X., Pan, J. P., and Li, Y. (1992). Artemisinin G: a sesquiterpene from Artemisia annua. Planta Med. 58, 300-300. doi: 10.1055/s-2006-961470

White, N. J. (2008). Qinghaosu (artemisinin): the price of success. Science 320, 330-334. doi: 10.1126/science. 1155165

Woerdenbag, H. J., Pras, N., Chan, N. G., Bang, B. T., Bos, R., van Uden, W., et al. (1994). Artemisinin, related sesquiterpenes, and essential oil in Artemisia annua during a vegetation period in Vietnam. Planta Med. 60, 272-275. doi: 10.1055/s-2006-959474

Wolfger, H., Mamnun, Y. M., and Kuchler, K. (2001). Fungal ABC proteins: pleiotropic drug resistance, stress response and cellular detoxification. Res. Microbiol. 152, 375-389. doi: 10.1016/S0923-2508(01) 01209-8

Xu, R., Fazio, G. C., and Matsuda, S. P. (2004). On the origins of triterpenoid skeletal diversity. Phytochemistry 65, 261-291. doi: 10.1016/j.phytochem.2003.11.014

Yazaki, K. (2005). Transporters of secondary metabolites. Curr. Opin. Plant Biol. 8 , 301-307. doi: 10.1016/j.pbi.2005.03.011

Yu, F., and De Luca, V. (2013). ATP-binding cassette transporter controls leaf surface secretion of anticancer drug components in Catharanthus roseus. Pro. Natl. Acad. U.S.A. 110, 15830-15835. doi: 10.1073/pnas.13075 04110

Zhang, L., Jing, F. Y., Li, F., Li, M. Y., Wang, Y. Y., Wang, G. F., et al. (2009). Development of transgenic Artemisia annua (Chinese wormwood) plants with an enhanced content of artemisinin, an effective anti-malarial drug, by hairpin-RNA-mediated gene silencing. Biotechnol. Appl. Biochem. 52, 199-207. doi: 10.1042/BA20080068

Conflict of Interest Statement: The authors declare that the research was conducted in the absence of any commercial or financial relationships that could be construed as a potential conflict of interest.

Copyright (c) 2017 Fu, Shi, He, Shen, Tang, Pan, Ma, Yan, Chen, Hao, Liu, Li, Wang, Sun and Tang. This is an open-access article distributed under the terms of the Creative Commons Attribution License (CC BY). The use, distribution or reproduction in other forums is permitted, provided the original author(s) or licensor are credited and that the original publication in this journal is cited, in accordance with accepted academic practice. No use, distribution or reproduction is permitted which does not comply with these terms. 